\title{
Comparative Diagnostic Accuracy Of ACE-III And MoCA For Detecting Mild Cognitive Impairment: A Letter To The Editor [Letter]
}

This article was published in the following Dove Press journal: Neuropsychiatric Disease and Treatment

\section{Ellen Richards \\ Olivia Knowles}

Department of Medicine, Barts and the London School of Medicine and Dentistry, London, UK
Correspondence: Ellen Richards Department of Medicine, Barts and the London School of Medicine and Dentistry, London, UK

Email richards@sel3.qmul.ac.uk

\section{Dear editor}

We read with interest the article by Wang et al, looking into the reliability and diagnostic accuracy of Addenbrooke's Cognitive Examination III (ACE-III), translated into Chinese, when looking at patients with mild cognitive impairment (MCI). The authors recruited 120 patients with MCI, and 136 healthy controls, and showed a positive correlation between ACE-III results and other common cognitive assessment methods (Montreal Cognitive Assessment (MoCA) and Mini-Mental State Examination (MMSE)). They also showed ACE-III to have higher diagnostic accuracy in detecting MCI when compared with the MMSE. ${ }^{1}$ We would like to thank the authors for highlighting the success of the Chinese version of ACE-III in diagnosing MCI and would like to offer some comments regarding their study.

The authors allude to the fact that they adapted some of the original ACE-III items, in order to improve understanding in the targeted Chinese population. For example, common English phrases and questions were replaced with popular Chinese culture, in order to avoid introducing any bias. However, it was unclear whether the authors had any guidance on this, or used evidence-based tools in order to aid their decisions. We would like to point the authors to a relevant systematic review by Mirza et al, which summarizes translation and cultural adaption of ACEIII from multiple papers. ${ }^{2}$ They conclude this review to be used as a guide to help translate and adapt ACE-III into different languages. This may have been helpful to the authors in ensuring correct translation of ACE-III into Chinese, and may be of use if they decide to replicate their study looking at the diagnostic accuracy of the Chinese version of ACE-III in other cognitive-impaired states.

Additionally, multiple studies have suggested that patient education level can have a direct effect on ACE-III total scores. ${ }^{3,4}$ One review also states age to be a consideration, with people over 75 scoring less in comparison with younger people. ${ }^{4}$ Wang et al show significant differences in age and education level in their study, with patients in the MCI group being, on average, 7.5 years older and 4.0 years more educated than their control counterparts. ${ }^{1}$ We agree with the authors that any further studies about the Chinese version of ACE-III should take education level into consideration, to avoid any bias due to patient population. It is also worth considering recruitment of patients groups with a more even distribution of age, in order to ensure age and education levels are not distorting future results. 


\section{Disclosure}

The authors report no conflicts of interest in this communication.

\section{References}

1. Wang B, Zheng H, Xu C, Sun Y, Zhang Y, Shi J. Comparative diagnostic accuracy of ACE-III and MoCA for detecting mild cognitive impairment. Neuropsychiatric DiseTreat. 2019;15:2647-2653. doi:10.2147/NDT.S212328

2. Mirza N, Panagioti M, Waheed M, Waheed W. Reporting of the translation and cultural adaptation procedures of the Addenbrooke's Cognitive Examination version III (ACE-III) and its predecessors: a systematic review. BMC MedRes Methodol. 2017;17(1). doi:10.1186/s12874-017-0413-6
3. Matías-Guiu J, Valles-Salgado M, Rognoni T, Hamre-Gil F, MorenoRamos T, Matías-Guiu J. Comparative diagnostic accuracy of the ACE-III, MIS, MMSE, MoCA, and RUDAS for screening of alzheimer disease. Dement Geriatr CognDisord. 2017;43(5-6):237-246. doi: $10.1159 / 000469658$

4. Bruno D, Schurmann Vignaga S. Addenbrooke's cognitive examination III in the diagnosis of dementia: a critical review. Neuropsychiatric Dis Treat. 2019;15:441-447. doi:10.2147/NDT.S151253

Dove Medical Press encourages responsible, free and frank academic debate. The content of the Neuropsychiatric Disease and Treatment 'letters to the editor' section does not necessarily represent the views of Dove Medical Press, its officers, agents, employees, related entities or the Neuropsychiatric Disease and Treatment editors. While all reasonable steps have been taken to confirm the content of each letter, Dove Medical Press accepts no liability in respect of the content of any letter, nor is it responsible for the content and accuracy of any letter to the editor.

\section{Publish your work in this journal}

Neuropsychiatric Disease and Treatment is an international, peerreviewed journal of clinical therapeutics and pharmacology focusing on concise rapid reporting of clinical or pre-clinical studies on a range of neuropsychiatric and neurological disorders. This journal is indexed on PubMed Central, the 'PsycINFO' database and CAS, and is the official journal of The International Neuropsychiatric Association (INA). The manuscript management system is completely online and includes a very quick and fair peer-review system, which is all easy to use. Visit http://www.dovepress.com/testimonials.php to read real quotes from published authors. 